(2) Open Access Full Text Article

\title{
Narrowband ultraviolet B light treatment changes plasma concentrations of MMP-3, MMP-9 and TIMP-3 in psoriatic patients
}

This article was published in the following Dove Press journal:

Therapeutics and Clinical Risk Management

27 April 2017

Number of times this article has been viewed

\author{
Edyta Katarzyna Głażewska' \\ Marek Niczyporuk' \\ Sławomir Ławicki ${ }^{2}$ \\ Maciej Szmitkowski² \\ Magdalena Donejko' \\ Monika Zajkowska ${ }^{2}$ \\ Grażyna Ewa Będkowska ${ }^{3}$ \\ Andrzej Przylipiak'
}

'Department of Esthetic Medicine,

${ }^{2}$ Department of Biochemical

Diagnostics, ${ }^{3}$ Department of

Haematological Diagnostics, Medical

University, Bialystok, Poland
Correspondence: Edyta Katarzyna

Głażewska

Department of Esthetic Medicine, Medical University, Bialystok, Akademicka 3,

I5-267 Bialystok, Poland

$\mathrm{Tel}+48857485822$

Email kasiaglazewska@wp.pl
Background: Matrix metalloproteinases (MMPs) and their tissue inhibitors (TIMPs) are thought to be associated with the pathogenesis and spread of psoriatic disease. This study was designed to investigate the plasma levels of MMP-3, MMP-9 and TIMP-3 in plaque psoriasis patients prior to and following a course of ultraviolet $\mathrm{B}$ narrowband treatment with respect to disease advancement.

Methods: Plasma samples of 49 patients suffering from plaque psoriasis and 40 healthy volunteers were evaluated. Concentrations of MMP-3, MMP-9 and TIMP-3 were determined using enzyme-linked immunosorbent assay, while Psoriasis Area and Severity Index was used to define disease advancement.

Results: Plasma levels of MMP-3, MMP-9 and TIMP-3 were significantly elevated in psoriasis patients compared to healthy individuals. A course of ultraviolet B narrowband treatment resulted in a significant decline in the studied metalloproteinases. Furthermore, the concentration of selected tissue inhibitors was negatively correlated with baseline Psoriasis Area and Severity Index score.

Conclusion: Our research highlights the meaningful role of MMP-3, MMP-9 and TIMP-3 in psoriasis pathogenesis and clearance of disease symptoms. Furthermore, plasma levels of the analyzed metalloproteinases seem to be a valuable psoriasis biomarker.

Keywords: gelatinase B, stromelysin 1

\section{Background}

Psoriasis is a chronic, immune-mediated, inflammatory skin disease, affecting 3\% of the world's population and requiring long-term treatment. ${ }^{1}$ The condition occurs with a different frequency according to ethnicity and geographic region. The disease is known to impair the patients' quality of life by causing considerable physical discomfort and psychological distress. ${ }^{2-4}$

The exact etiopathogenesis of psoriasis remains unidentified. It is assumed that the development of psoriatic scales may be triggered by several environmental factors, a genetic predisposition or medication. It may also be associated with other diseases. To date, a number of factors of potential importance in the pathogenesis and spread of the condition have been proposed. ${ }^{5}$ Having analyzed the data presented in the available literature, we hypothesized that matrix metalloproteinases (MMPs) and their tissue inhibitors may be one of these factors.

MMPs are a family of metal-dependent $\left(\mathrm{Zn}^{2+}, \mathrm{Ca}^{2+}\right)$ enzymes that are classified based on their minor structural differences and substrate specificity into the following subgroups: collagenases, gelatinases, stromelysins, matrilysins, transmembrane MMPs,

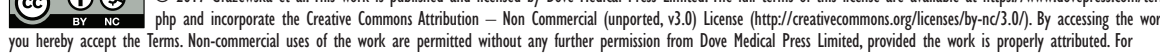

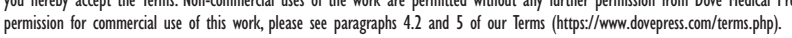


"other MMPs" and ADAM metalloproteinases. ${ }^{6}$ These proteins are involved in a number of physiologic and pathologic processes, thanks to their remarkable ability to degrade and rebuild proteins forming the extracellular matrix and the basal membrane. ${ }^{7}$ MMPs have been found to be implicated in psoriasis pathogenesis by changing intracellular contacts, extracellular matrix and basal membrane components, cleaving, promoting the formation of new vessels and stimulating immune cells infiltration. Fibroblasts, endothelial cells, keratinocytes, infiltrating immune cells and cancer cells are the main sources of MMPs in the human body. ${ }^{8}$

The adverse effects of MMPs overexpression are suppressed by their tissue inhibitors (TIMPs), a group which comprises four members among mammals. ${ }^{9}$ What is significant, the physiologic MMP:TIMP ratio is strictly defined and any disturbance in this proportion affects tissue homeostasis and the maintenance and function of skin cells in extreme conditions. ${ }^{10}$

Since its first application in 1988, narrowband ultraviolet B (NBUVB) therapy has become one of the safest and most commonly utilized methods of psoriasis treatment. The method is also highly effective since a reduction in psoriatic scales with the use of UVB-311 nm light can be achieved after as short a period of time as 5-8 weeks. The treatment is recommended as a second-line psoriasis therapy when the first-line therapy fails or is contraindicated or impractical. ${ }^{11}$

Considering the fact that psoriatic biomarkers presented in the available literature are not entirely specific or sensitive, researchers are attempting to find parameters implicated in the pathogenesis of psoriasis, whose levels would correlate more closely with disease presence and severity. In this study, we examined the plasma levels of MMP-3 (stromelysin 1), MMP-9 (gelatinase B) and TIMP-3 in psoriatic patients with respect to disease advancement. Moreover, we aimed to reveal the impact of the commonly administered NBUVB treatment on the concentration of selected parameters.

\section{Materials and methods}

Table 1 shows the tested groups. This prospective study included 49 plaque psoriasis patients whose condition was diagnosed and treated in the Outpatient Clinic of the Department of Dermatology, University Hospital, Bialystok, Poland, between 2013 and 2015. Participants were assigned to specific groups of disease advancement on the basis of Psoriasis Area and Severity Index (PASI) formulated by Fredriksson and Pettersson. ${ }^{12}$ Furthermore, patients with a
Table I Characteristics of psoriatic patients and the control group

\begin{tabular}{ll}
\hline Study group & Number of patients \\
\hline Psoriasis patients & \\
Plaque type & 49 (23 females, 26 males) \\
Median age (range) & $39(18-76)$ \\
Severity & 34 \\
$\quad$ Mild & 15 \\
$\quad$ PASI $<5$ & 19 \\
$\quad$ PASI 5-10 & 15 \\
Moderate & 15 \\
$\quad$ PASI $>$ I0-<30 & \\
Control group & 40 (19 females, 2I males) \\
Healthy subjects & $36(18-75)$ \\
Median age (range)
\end{tabular}

Note: Reproduced from Głażewska EK, Niczyporuk M, Ławicki S, et al. Therapy Of Psoriasis With Narrowband Ultraviolet-B Light Influences Plasma Concentration Of MMP-2 And Timp-2 In Patients. Ther Clin Risk Manag. 2016;12:1579-1585. ${ }^{29}$ Abbreviation: PASI, Psoriasis Area and Severity Index.

mild form of the disease were divided into two subgroups - Ia (PASI <5) and Ib (PASI 5-10).

All patients underwent a course of NBUVB phototherapy consisting of 20 sessions. Considering the fact that this kind of treatment is suitable for patients with mild and moderate forms of psoriasis, the study included patients with a PASI score between 2 and 30 .

The control group consisted of 40 healthy volunteers who had never suffered from any autoimmunologic or chronic dermatologic diseases. The key exclusion criterion in both groups was any additional pharmacotherapy.

All patients gave their informed consent for participation in the study. The study was approved by the Biochemical Committee of the Medical University of Bialystok (No R-I002/74/2014).

\section{Radiation source}

Whole-body irradiation was performed in a Cosmedico GP-36 phototherapy cabinet (Cosmedico Medical System, Stuttgart, Germany), equipped with NBUVB 311 nm TL-01 100W tubes (Heine.Med, Baden-Württemberg, Germany). The energy output was measured with a standard intrinsic UV meter.

\section{Phototherapy protocol}

Individual minimum erythema doses of NBUVB were determined prior to the commencement of exposure to prevent burns. The patients underwent two to three treatments weekly (up to a total number of 20), starting with an NBUVB dose of $0.018-0.025 \mathrm{~J} / \mathrm{cm}^{2}$ and increasing it by $\sim 10 \%-20 \%$ per week, up to a maximum dose of $2.015 \mathrm{~J} / \mathrm{cm}^{2}$. 


\section{Biochemical analyses}

Venous blood samples were collected from each patient twice - prior to the commencement and following the last (20th) NBUVB phototherapy treatment - into a heparin sodium tube, centrifuged for $15 \mathrm{~min}$ at $1,000 \times \mathrm{g}$ to obtain plasma samples and stored at $-85^{\circ} \mathrm{C}$ until the assay. The tested parameters were measured with enzyme-linked immunosorbent assay (MMP-3 and MMP-9 with Quantikine Human HGFs Immunoassay, R\&D Systems, Inc., Minneapolis, MN, USA; TIMP-3 with Quantikine Human MMP-3 Immunoassay, Wuhan EIAab Science Co., Wuhan, People's Republic of China), according to the manufacturer's protocols. Duplicate samples were assessed for each patient.

The intraassay coefficient of variation (CV\%) of MMP-3 is reported to be $6.1 \%$ at a mean concentration of $3.21 \mathrm{ng} / \mathrm{mL}$, standard deviation $(\mathrm{SD})=0.197$, for MMP-9 $1.9 \%$ at a mean concentration of $2.04 \mathrm{ng} / \mathrm{mL}, \mathrm{SD}=0.039$ and for TIMP-3 it is $6.1 \%$.

The interassay coefficient of variation (CV\%) of MMP-3 is reported to be $7.0 \%$ at a mean concentration of $3.08 \mathrm{ng} / \mathrm{mL}$, $\mathrm{SD}=0.217$, for MMP-9 $7.8 \%$ at a mean concentration of $2.35 \mathrm{ng} / \mathrm{mL}, \mathrm{SD}=0.184$ and for TIMP-3 it is $8.4 \%$.

The assay showed no significant cross-reactivity or interference with numerous human cytokines and other growth factors.

\section{Statistical analysis}

Statistical analysis was performed using STATISTICA 12.0 PL Program. Preliminary statistical analysis revealed that MMP-3, MMP-9 and TIMP-3 failed to follow a normal distribution. Consequently, the Mann-Whitney $U$ test was used for comparative statistical analysis between psoriatic patients and the control group. Additionally, statistical analysis between the groups with different severity of psoriasis was performed with the use of the Bonferroni correction. Moreover, the Wilcoxon matched pair test was used for statistical analysis of changes in parameters occurring throughout the period of the NBUVB phototherapy treatment. The data were presented as median, mean and range. Spearman rank correlation was used in correlation analysis. Statistically significant differences were defined as comparisons resulting in $P<0.05$.

\section{Results}

Mean PASI value of patients enrolled in the study was 8.53 (range 2.0-25.0). After the completion of the treatment, the mean PASI decreased to 4.74 (range 0-18.2). Mean PASI improvement was $52 \%$.
Plasma levels of MMP-3, MMP-9 and TIMP-3 are summarized as the mean, median value and range in Table 2. Prior to the commencement of NBUVB treatment, the concentrations of all the analyzed parameters were significantly elevated in the total psoriatic patients group when compared to the healthy controls.

Following the classification of the total group according to disease severity, we found significantly increased levels of MMP-3 and MMP-9 in subjects with moderately severe psoriasis in comparison with the healthy controls. Moreover, significantly higher concentrations of the tested inhibitor were found in the patients with mild scales and in subjects from subgroup Ia, when compared to healthy individuals.

A comparison of the subgroups of untreated psoriatic subjects showed significant differences in TIMP-3 levels between mild and moderate cases, between subgroups Ia and $\mathrm{Ib}$ and between patients from subgroup Ia and subjects with moderately severe psoriasis.

Spearman rank correlations were used to explore the associations between selected factors. Pretreatment $(R=0.26, P<0.05$; Figure 1$)$ as well as posttreatment ( $R=0.22, P<0.05$; Figure 2) plasma levels of TIMP-3 were positively correlated with the analogous concentrations of MMP-9. Also, the levels of the selected factors were negatively correlated with a PASI score $(R=-0.54$, $P<0.05$; Figure 3$)$ and positively correlated with the age of the studied individuals $(R=0.30, P<0.05)$, both prior to the commencement and following the completion of NUVB treatment $(R=-0.30, P<0.05$ and $R=0.42, P<0.05$, respectively). Furthermore, we noticed a positive correlation between the pretreatment plasma levels of MMP-3 and the cohorts' sex $(R=0.53, P<0.05)$.

A course of 20 NBUVB radiation treatments influenced the concentrations of the tested parameters. Following treatment competition, the plasma levels of MMP-3 and MMP-9 in the total group of psoriatic patients were statistically significantly lower than prior to the commencement of therapy. In contrast, the concentration of TIMP-3 in the total group increased, but this change was not significant.

Interestingly, only TIMP-3 posttreatment values were significantly higher in the total group, subjects with a mild form of the disease and both subgroups, when compared to the controls. Analogous to the pretreatment correlations, we found statistically significant differences of TIMP-3 posttreatment levels between the groups of mild and moderate cases, between the patients from subgroups Ia and Ib and between subgroup Ia individuals and moderately severe cases. 
Table 2 Plasma levels of tested parameters in psoriatic patients and the control group

\begin{tabular}{|c|c|c|c|c|c|c|}
\hline \multirow[t]{2}{*}{ Groups tested } & \multicolumn{2}{|c|}{ MMP-3 (ng/mL) } & \multicolumn{2}{|c|}{ MMP-9 (ng/mL) } & \multicolumn{2}{|l|}{ TIMP-3 (ng/mL) } \\
\hline & $\begin{array}{l}\text { Before } \\
\text { treatment }\end{array}$ & $\begin{array}{l}\text { After } \\
\text { treatment }\end{array}$ & $\begin{array}{l}\text { Before } \\
\text { treatment }\end{array}$ & $\begin{array}{l}\text { After } \\
\text { treatment }\end{array}$ & $\begin{array}{l}\text { Before } \\
\text { treatment }\end{array}$ & $\begin{array}{l}\text { After } \\
\text { treatment }\end{array}$ \\
\hline \multicolumn{7}{|l|}{ Psoriatic patients } \\
\hline Total group & $a, c$ & & $a, c$ & & $\mathbf{a}$ & $\mathbf{a}$ \\
\hline Median & 14.97 & 14.70 & 73.47 & 57.39 & 562.0 & 608.39 \\
\hline Mean & 18.80 & 15.86 & 112.42 & 77.72 & 845.03 & 821.50 \\
\hline Range & $2.96-49.2$ & $1.36-39.57$ & $10.86-569.8$ & $6.41-336.49$ & $246.78-2,340.92$ & $235.50-2,377.03$ \\
\hline Mild & & & & & a,d & a,d \\
\hline Median & 13.73 & 13.00 & 72.82 & 52.93 & $1,021.28$ & 763.23 \\
\hline Mean & 16.88 & 14.47 & 108.87 & 66.60 & $1,005.39$ & 946.47 \\
\hline Range & $2.96-49.20$ & I.36-32.46 & $10.86-569.80$ & $6.40-195.00$ & $246.78-381.67$ & $381.67-2,377.03$ \\
\hline Mild - subgroup la & & & $\mathbf{a}$ & & a,b,e & a,b \\
\hline Median & $|2.5|$ & 12.19 & 82.00 & 57.39 & $1,286.69$ & $\mathrm{I}, 154.15$ \\
\hline Mean & 15.78 & 13.53 & 134.76 & 75.62 & $|, 35| .44$ & $11,61.67$ \\
\hline Range & $4.19-49.20$ & $2.52-26.64$ & $25.87-569.80$ & $37.69-193.29$ & $490.7 \mathrm{I}-2,340.92$ & $447.90-2,323.39$ \\
\hline Mild - subgroup lb & & & & & & a \\
\hline Median & 14.52 & 15.82 & 67.61 & 49.84 & 537.5 & 492.33 \\
\hline Mean & 17.75 & 15.22 & 88.43 & 59.46 & 732.19 & 776.58 \\
\hline Range & $2.96-48.42$ & $1.36-32.46$ & $10.86-306.54$ & $6.41-195.00$ & |246.78-I,725.5। & $381.67-2,377.03$ \\
\hline Moderate & $a, c$ & & $\mathbf{a}$ & & & \\
\hline Median & 22.04 & 19.15 & 91.36 & 72.23 & 453.96 & 491.92 \\
\hline Mean & 23.13 & 19.00 & 120.48 & 102.93 & 481.57 & 538.23 \\
\hline Range & $7.95-46.91$ & $5.60-39.58$ & $21.77-318.012$ & $31.78-336.49$ & $335.42-940.85$ & $235.50-1,137.75$ \\
\hline \multicolumn{7}{|l|}{ Control group } \\
\hline \multicolumn{7}{|l|}{ Healthy subjects } \\
\hline Median & 13.04 & & 49.46 & & 411.63 & \\
\hline Mean & 13.33 & & 65.44 & & 431.63 & \\
\hline Range & $2.76-32.05$ & & $12.84-233.88$ & & $287.66-753.27$ & \\
\hline
\end{tabular}

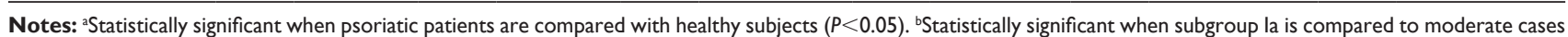

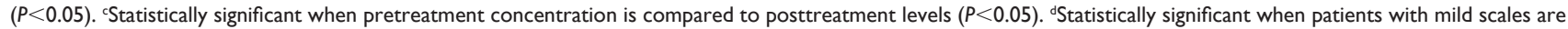

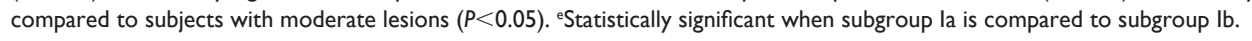

Abbreviations: MMP, matrix metalloproteinase; TIMP, tissue inhibitor of metalloproteinase.

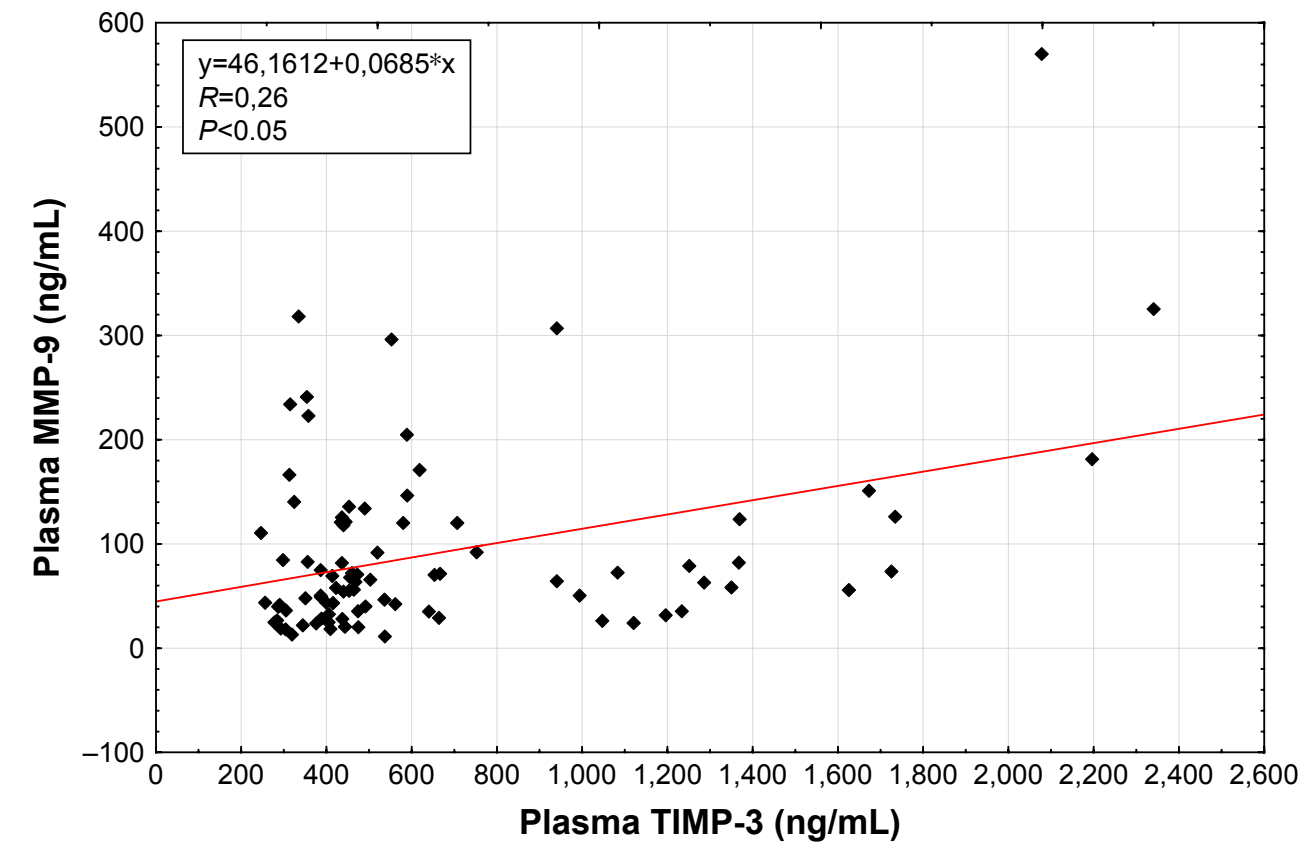

Figure I Correlation of baseline plasma MMP-9 with baseline plasma TIMP-3 in patients with psoriasis. Abbreviations: MMP, matrix metalloproteinase; TIMP, tissue inhibitor of metalloproteinase. 


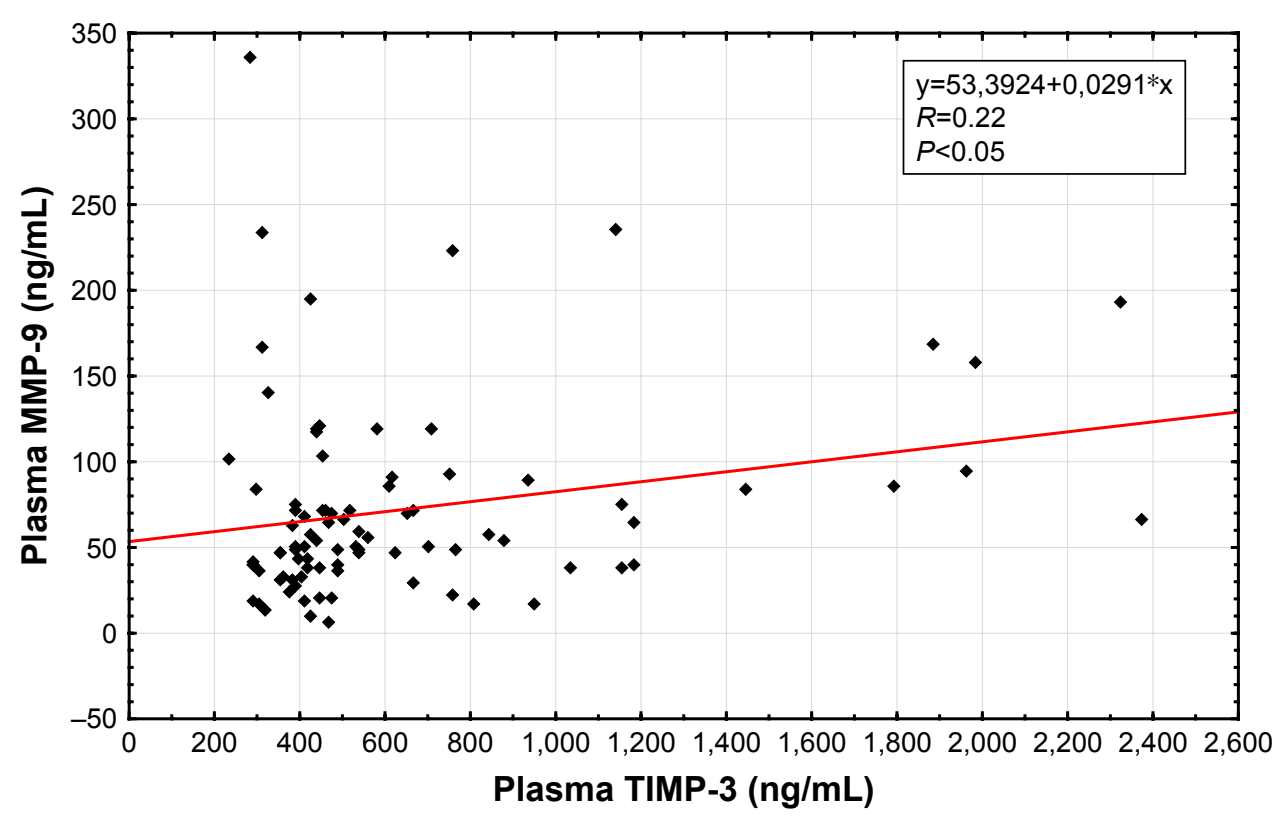

Figure 2 Correlation of posttreatment plasma MMP-9 with posttreatment plasma TIMP-3 in patients with psoriasis. Abbreviations: MMP, matrix metalloproteinase; TIMP, tissue inhibitor of metalloproteinase.

\section{Disscusion}

The multifunctionality of MMPs condition their implication in a variety of physiologic processes, which include angiogenesis, embryogenesis and wound healing. On the other hand, significant disturbances in the concentration and activity of the analyzed endopeptidases have been detected among patients suffering from, for example, inflammatory and degenerative conditions, cancer, skin and kidney diseases. ${ }^{13}$
MMP-9, belonging to the gelatinases subfamily, is distinct from the other MMPs, thanks to its ability to digest elatins, collagen types I, IV, V, VII, XI and aggrecans. Moreover, the described factor takes part in interleukin (IL)-1 and plasminogen activation. In contrast, stromelysin 1 does not degrade fibrillar collagen, although it possesses a unique ability to activate MMP- $1,-3,-7,-8,-9$ and -13 proenzymes. ${ }^{8,14-16}$

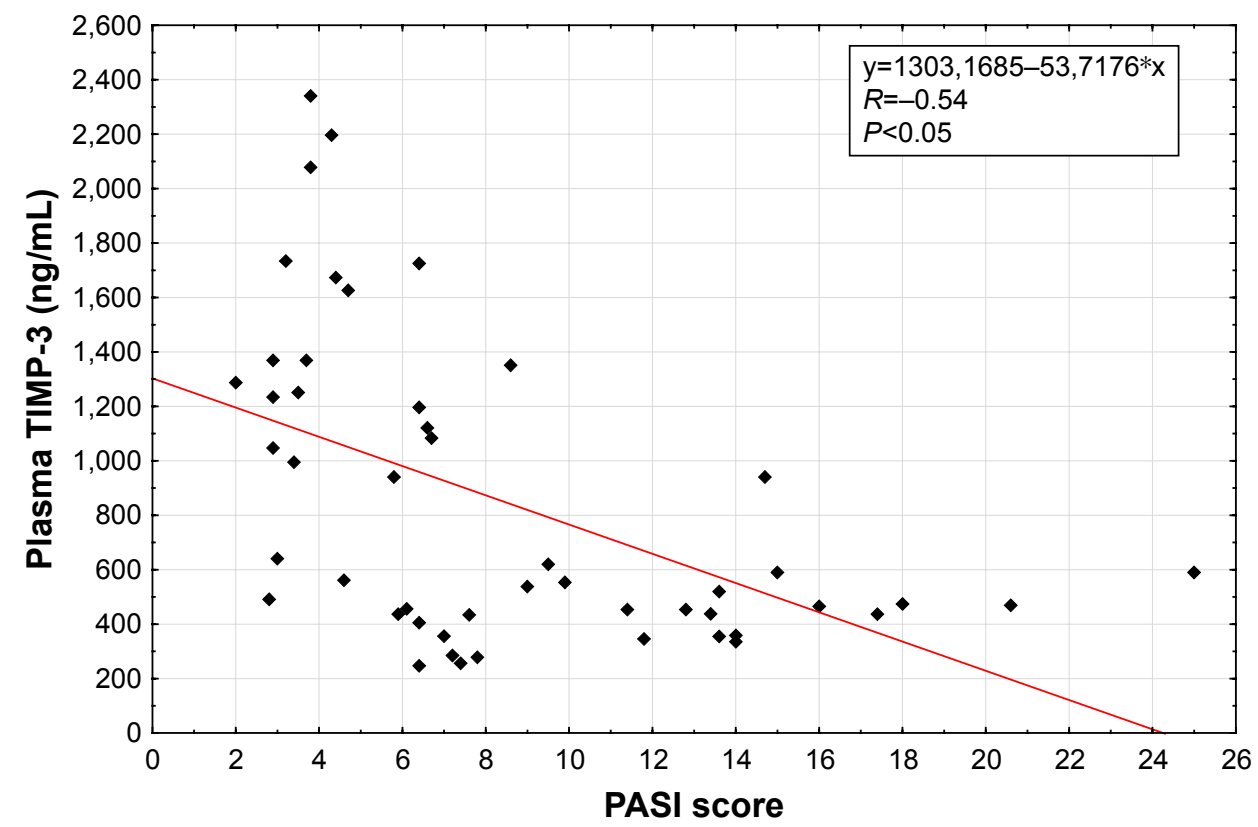

Figure 3 Correlation of baseline plasma TIMP-3 with baseline PASI in patients with psoriasis. Abbreviations: PASI, Psoriasis Area And Severity Index; TIMP, tissue inhibitor of metalloproteinase. 
MMPs are inhibited by TIMPs, one which TIMP-3 efficiently inhibits membrane-type metalloproteinases. Remarkably, this factor is also the most effective inhibitor of MMP-9 among all TIMPs. ${ }^{17}$

The clinical manifestations of psoriasis are associated with modifications in the cellular composition of the epidermis by the infiltrating immune cells. Interestingly, the eruption of the disease results in the migration of $\sim 20$ million of the total 28-30 million body lymphocytes to the sites of damage. The dermis contains an inflammatory infiltrate composed of lymphocytes, macrophages, mast cells and neutrophils. ${ }^{18,19}$ Altered MMP production may occur as a consequence of the disturbed cytokine synthesis (eg, tumor necrosis factor-alpha, IL-1, interferon- $\gamma$, IL-6, TGF- $\alpha$, EGF) by those cells. ${ }^{20}$

Our research demonstrated that the levels of MMP-9 and MMP-3 were significantly higher in the plasma of psoriatic patients compared to those of healthy individuals, and the value of this concentration increased with disease advancement. Elevated plasma levels of gelatinase B were also detected among an analogous cohort by Altrichter et $\mathrm{al}^{21}$ and Sigurdardottir et al. ${ }^{22}$ Moreover, the overexpression of this factor in psoriatic skin has been repeatedly confirmed by other researchers. ${ }^{23,24}$ Furthermore, an increased concentration of MMP-3 has been found in the sera of psoriatic subjects. ${ }^{25}$

A study conducted by Altrichter et al suggested that the general inflammatory status, that is, a combination of cell destruction, inflammatory cells migration and tissue remodeling, occurring in the course of psoriasis resulted in an increase in MMP-9 plasma levels. ${ }^{21}$ Reiss et al were the first to report that the overexpression of MMP-9 was strongly correlated with skin damage and its expression declined rapidly in response to the healing of lesions in a mouse model. Furthermore, they proved that a chronically elevated gelatinase B level delayed wound healing. ${ }^{26}$ Interestingly, a different research group has advocated that the upregulation of MMP-3 suppresses dermis contraction and prolongs the wound healing process. ${ }^{27}$ The data obtained in our study appear significant since we demonstrated that the concentrations of gelatinase B and stromelysin 1 stimulate the growth and spread of psoriatic scales.

Additionally, in this study, we observed a significantly elevated level of TIMP-3 in the analyzed group compared to the controls. These findings are in accordance with data from other available studies. As previously stated, TIMP-3 is the most effective suppressor of MMP-9. Moreover, our findings releaved a strong positive correlation between these factors. Interestingly, we also found a negative correlation between TIMP-3 levels and disease advancement. These findings prove the hypothesis that elevated MMP-9 levels, increasing with the advancement of psoriasis without a relevant increase in its tissue inhibitor levels, contribute to the development of the condition.

Studies concerning other metalloproteinases and tissue inhibitors have also been conducted in the plasma of psoriasis patients. In our previous research, we detected elevated levels of MMP-2 with no significant changes in TIMP-2 concentration, and decreased levels of MMP-12, while Flisiak et al pointed to a significantly elevated concentration of MMP-1 and TIMP-1 in psoriatic patients when compared to healthy subjects. ${ }^{28-30}$ These findings indicate a strong relationship between the analyzed condition and changes in the concentrations of MMPs and TIMPs.

The efficacy of UVB narrowband phototherapy in the treatment of psoriasis and a number of other skin disorders is determined by a multisite action of this type of treatment, which includes alteration of the cytokine profile, induction of apoptosis and promotion of immunosuppression. ${ }^{11,31}$ Furthermore, the clinical improvement of psoriasis achieved by NBUVB is associated with the downregulation of the IL-17 pathway and also, type I and type II interferon signaling pathways, which is crucial to the pathogenesis of the condition. Additionally, a clinically effective NBUVB therapy involves the suppression of numerous significant molecular pathways in psoriatic skin. ${ }^{32,33}$

In this study, we found that a successful NBUVB course resulted in a significant decline in MMP-3 and MMP-9 concentrations. Simultaneously, the phototherapy treatment caused an increase in TIMP-3 levels, although this change was not statistically significant. Our results are in line with those obtained by other authors who analyzed the influence of different kinds of psoriasis treatment on these parameters. ${ }^{8,34}$ In contrast, a study by Sigurdardottir et al did not find significant changes in MMP-9 concentration after NBUVB treatment. ${ }^{22}$ Moreover, other studies have demonstrated that NBUVB causes a decrease in plasma MMP-2 levels as well as a reduction in psoriatic scales. ${ }^{29,35}$

As it was previously highlighted, the available literature demonstrates that the wound healing process is strongly connected with the levels of selected endopeptidases. Our study is the first one to show that the plasma concentrations of MMP-3 and MMP-9 increase together during disease eruption and decline significantly after successful treatment, which constitutes convincing proof of a connection between the analyzed factors and the healing process of psoriatic lesions. 


\section{Conclusion}

In summary, elevated levels of MMP-3, MMP-9 and TIMP-3 occurring during psoriasis eruption and significant decline of mentioned metalloproteinases following successful NBUVB treatment resulting in the clearance of the disease symptoms indicate that these proteins are implicated in the etiopathogenesis and spread of the condition. Therefore, plasma concentrations of gelatinase $B$ and stromelysin 1 , and TIMP-3 appear to be a valuable candidate as the biomarkers of psoriasis.

\section{Acknowledgment}

This work was supported by grants from the Medical University of Białystok (143-30737F and N/ST/MN/16/ 001/2230).

\section{Disclosure}

The authors report no conflicts of interest in this work.

\section{References}

1. Gooderham MJ, Poulin-Costello M, Shelton J, Bayan N, Papp KA. Predictors of topical use in psoriasis patients in the REFINE Study. J Cutan Med Surg. 2016;20(2):106-112.

2. Parisi R, Symmons DPM, Griffiths CEM, et al. Global epidemiology of psoriasis: a systematic review of incidence and prevalence. $J$ Invest Dermatol. 2013;133:377-385.

3. Cohen BE, Martires KJ, Ho RS. Psoriasis and the risk of depression in the US population: National Health and Nutrition Examination Survey 2009-2012. JAMA Dermatol. 2016;152(1):73-79.

4. Huerta C, Rivero E, Rodríguez LA. Incidence and risk factors for psoriasis in the general population. Arch Dermatol. 2007;143(12): 1559-1565.

5. Boehncke WH. Etiology and pathogenesis of psoriasis. Rheum Dis Clin North Am. 2015;41(4):665-675.

6. Kapoor C, Vaidya S, Wadhwan V, Hitesh, Kaur G, Pathak A. Seesaw of matrix metalloproteinases (MMPs). J Cancer Res Ther. 2016;12(1): $28-35$.

7. Shay G, Lynch CC, Fingleton B. Moving targets: emerging roles for MMPs in cancer progression and metastasis. Matrix Biol. 2015 44-46:200-206.

8. Mezentsev A, Nikolaev A, Bruskin S. Matrix metalloproteinases and their role in psoriasis. Gene. 2014;540(1):1-10.

9. Arpino V, Brock M, Gill SE. The role of TIMPs in regulation of extracellular matrix proteolysis. Matrix Biol. 2015;44-46:247-254.

10. Sartakhti JS, Manshaei MH, Sadeghi M. MMP-TIMP Interactions in cancer invasion: an evolutionary game-theoretical framework $J$ Theor Biol. 2017;412:17-26.

11. Racz E, Prens EP. Phototherapy and photochemotherapy for psoriasis. Dermatol Clin. 2015;33(1):79-89.

12. Fredriksson T, Pettersson U. Severe psoriasis oral therapy with a new retinoid. Dermatologica. 1978;157(4):238-244.

13. Galliera E, Tacchini L, CorsiRomanelli MM. Matrix metalloproteinases as biomarkers of disease: updates and new insights. Clin Chem Lab Med. 2015;53(3):349-355.

14. Ławicki S, Zajkowska M, Głażewska EK, Bedkowska GE, Szmitkowski M. Plasma levels and diagnostic utility of VEGF, MMP-9, and TIMP-1 in the diagnosis of patients with breast cancer. Onco Targets Ther. 2016;9:911-919.
15. Ławicki S, Głażewska EK, Sobolewska M, Bedkowska GE, Szmitkowski M. Plasma levels and diagnostic utility of macrophage colony-stimulating factor, matrix metalloproteinase-9, and tissue inhibitor of metalloproteinases- 1 as new biomarkers of breast cancer. Ann Lab Med. 2016;36(3):223-229.

16. McCawley LJ, Matrisian LM. Matrix metalloproteinases: they're not just for matrix anymore! Curr Opin Cell Biol. 2001;13(5):534-540.

17. Nagase H, Visse R, Murphy G. Structure and function of matrix metalloproteinases and TIMPs. Cardiovasc Res. 2006;69(3):562-573.

18. Ayala-Fontánez N, Soler DC, McCormick TS. Current knowledge on psoriasis and autoimmune diseases. Psoriasis Targets Ther. 2016; $6: 7-32$

19. Heidenreich R, Röcken M, Ghoreschi K. Angiogenesis drives psoriasis pathogenesis. Int J ExpPathol. 2009;90(3):232-248.

20. Eysteinsdóttir JH, Sigurgeirsson B, Ólafsson JH, et al. Therole of Th17/ Tc17peripheral blood $\mathrm{T}$ cells in psoriasis and their positive therapeutic response. Scand J Immunol. 2013;78(6):529-537.

21. Altrichter S, Boodstein N, Maurer M. Matrix metalloproteinase-9: a novel biomarker for monitoring disease activity in patients with chronic urticaria patients? Allergy. 2009;64(4):652-656.

22. Sigurdardottir G, Ekman AK, Ståhle M, Bivik C, Enerback C. Systemic treatment and narrowband ultraviolet B differentially affect cardiovascular risk markers in psoriasis. $J$ Am Acad Dermatol. 2014;70(6): 1067-1075.

23. Fleischmajer R, Kuroda K, Hazan R, et al. Basement membrane alterations in psoriasis are accompanied by epidermal overexpression of MMP-2 and its inhibitor TIMP-2. J Invest Dermatol. 2000;115(5): 771-777.

24. Simonetti O, Lucarini G, Goteri G, et al.VEGF is likely a key factor in the link between inflammation and angiogenesis in psoriasis: results of an immunohistochemical study. Int J Immunopathol Pharmacol. 2006; 19(4):751-760.

25. Chandran Y, Cook RJ, Edwin J, et al. Soluble biomarkers differentiate patients with psoriatic arthritis from those with psoriasis without arthritis. Rheumatology (Oxford). 2010;49(7):1399-1405.

26. Reiss MJ, Han YP, Garcia E, et al. Matrix metalloproteinase-9 delays wound healing in a murine wound model. Surgery. 2010;147: 295-302.

27. Bullard KM, Lund L, Mudgett JS, et al. Impaired wound contraction in stromelysin-1-deficient mice. Ann Surg. 1999;230(2):260-265.

28. Głażewska EK, Niczyporuk M, Przylipiak A, et al. Influence of narrowband ultraviolet-B phototherapy on plasma concentration of matrix metalloproteinase - 12 In psoriatic patients. Postep Derm Alergol. In press, 2017

29. Głażewska EK, Niczyporuk M, Ławicki S, et al. Therapy Of Psoriasis With Narrowband Ultraviolet-B Light Influences Plasma Concentration Of MMP-2 And Timp-2 In Patients. Ther Clin Risk Manag. 2016; 12:1579-1585.

30. Flisiak I, Porebski P, Chodynicka B. Effect of psoriasis activity on metalloproteinase-1 and tissue inhibitor of metalloproteinase-1 in plasma and lesional scales. Acta Derm Venereol. 2006;86(1):17-21.

31. Reich A, Mędrek K. Effects of narrow band UVB $(311 \mathrm{~nm})$ irradiation on epidermal cells. Int J Mol Sci. 2013;14(4):8456-8466.

32. Rácz E, Prens EP, Kurek D, et al. Effective treatment of psoriasis with narrow-band UVB phototherapy is linked to suppression of the IFN and Th17 pathways. J Invest Dermatol. 2011;131(7):1547-1558.

33. Richard EG, Hönigsmann H. Phototherapy, psoriasis, and the age of biologics. Photodermatol Photoimmunol Photomed. 2014;30(1):3-7.

34. Buommino E, De Filippis A, Gaudiello F, et al. Modification of osteopontin and MMP-9 levels in patients with psoriasis on anti-TNF-alpha therapy. Arch Dermatol Res. 2012;304(6):481-485.

35. FuMin L, Xue W, XiLing D, et al. Action mechanism of narrow-band ultraviolet $\mathrm{B}$ on vascular regulatory factors in psoriasis vulgaris. Chin $J$ Dermatol. 2009;42:163-166. 


\section{Publish your work in this journal}

Therapeutics and Clinical Risk Management is an international, peerreviewed journal of clinical therapeutics and risk management, focusing on concise rapid reporting of clinical studies in all therapeutic areas, outcomes, safety, and programs for the effective, safe, and sustained use of medicines. This journal is indexed on PubMed Central, CAS,

EMBase, Scopus and the Elsevier Bibliographic databases. The manuscript management system is completely online and includes a very quick and fair peer-review system, which is all easy to use. Visit http://www.dovepress.com/testimonials.php to read real quotes from published authors.

Submit your manuscript here: http://www.dovepress.com/therapeutics-and-clinical-risk-management-journal 